affected bowel was resected. The patient was given massive doses of steroids, antibiotics, and fluid replacement for septicaemic shock and gradually recovered. Clinical features of myxoed recovered. Clinical features of myxoedema were then apparent and this was confirmed by iodin studies. The patient's appearance and bowel habit returned to normal with thyroxine. Histologically, ischaemic colitis.

Constipation and abdominal distension are well-recognized features of hypothyroidism. Gross colonic dilatation in this patient was followed by mucosal ischaemia and necrosis, allowing the development of septicaemic shock secondary to invasive infection. The usually fatal outcome in this condition was avoided by prompt excision of the diseased bowel and intensive therapy for septicaemic shock.-We are, etc.

V. R. KALE

D. A. K. WOODWARD

George Eliot Hospital,

Nuneaton

1 Chadda, J. S., Ashby, D. W., and Cowan, W. K., British Medical fournal, 1969, 3, 398.

Surgical Clinics of North", America, Surgical

3 Marston, A., et al., Gut, 1966, 7, 1.

Conversations on the Social Services

SIR,-I centainly sympathize with some of your special correspondent's criticisms of local authority social services depantments (22 June, p. 659) but am glad he appreciates some of our difficulties. Time will doubtless heal the wounds and disabiaities inflioted by all the recent reorganization, not least of which are this year's local government and N.H.S. restruoturings. However, as we all strive to practise the flexible community-oriented care which the 1972 N.H.S. White Paper outlined "to provide fior the population of a given area of a comprehensibue size the best health service that the money and skills available can provide,"l we realize only too clearly that much of the work of a social services department does indeed present in the general practitioner's surgery.

While social workers do understand the "threat" they and their rapidly developing bureaucracies pose to the single-handed practitioner and the frustration this everchanging personnel and structures can cause, they equally feel threatened by those doctors who remain on their "professional pedestals." One of the major problems can be lack of accurate and perceptive communication between us when we employ fundamentally different jargen and philosophies, dootors being accused of being unnecessarily brusque and social workers as being hopelessly longwinded.

It is essential that we talk pumposefully together. While the case conference offers a valuable avenue, it can be abused when utilized in the way your oorrespondent describes, and both professions are guilty of that. It should be used only where appropriate and in the enhancement of increasingly necessary interdisciplinary teamwork, both within and outside the hospital. Until the principle of linking social workers in social services departments with group practices is fully accepted by both doctors and social services administrators alike the most functional type of communication must be individual contact, preferably face-to-face, as the needs arise. In that way we can, it is to be hoped, get to know each other better.

In our patients' best interests, therefore, we can do our jobs realistically only by mutual colwaboration. That means remembering that it was our own Seebohm Report which exhorted social services departments to "make a determined effort to collaborate with local general practitioners," and similarly that the authors hoped that "the doctors will also exert themselves." 2 It was, after all, that very repon which reminded us that G.P.s see "a higher proportion of those who are in difficulties than any other of the social services" and they accordingly need "the full support of them all."3

Incidentally, some of my best friends are G.P.s-I am, etc.,

Northwood, Middlesex

JENNIFER A. H. FRANCIS

1 National Health Service Reorganization: England, p. vi, Cmnd. 5055. London, H.M.S.O., 1972.

Social Services, Report, para. 700, Cmnd. Social Services, Report, para.

Committee on Local Authority and Allied Personal

Social Services, Report, para. 692, Cmnd. 3703
London, H.M.S.O., 1968.

SIR. -As a health visitor may I comment on "Conversations on the Social Services" (15 June, p. 595). There is indeed some overlap between social workers and health visitors since both may be supponting the same client. However, the health visitor is primarily ooncenned with prevention and early deteotion of illness, bath physical and social, and works with normal families to a greater extent than the social worker.

I should not like your neaders to gain the impression that the health visitor is to be regardied as a second-best social worker. Before Seebohm we had in fact several dutives that have now been ascribed to the social services depantments. Those of us attached to general practices often act as a liaison between the practice and the statutory and voluntary social services in the area. I would also nemind your readers that all health visitors hold the S.R.N. and health visitor certificates, as well as having some training in midwifery. The majority of social workers still have no professional qualification.-I am, etc.,

Hampton, Middlesex

Patricia Scowen

\section{Medicine in China}

SIR,-Dr. I. Gordion (22 June, p. 674) has questioned the epidemiological sense of the concurnent observations that at the present time cervical cancer is common in China while premarital intencourse, venteneal disease, and early marniage ane reported to be very rane and frowned upon. This confusion ignores the obvious latent or incubation period between cervical cancer and the antecedent sexual behaviour. Dr. Valerie Beral ${ }^{1}$ has most elegantly and convincingly demonstrated that the mortality rate for cervical cancer for an age group mirrors the reported incidence of gonococcal veneneal disease for the period during which that age group was about 20 years old, based on data for the British Isles. Thus cases of cervical cancer identified today would nefleot the sexual activity of 15-20 or more years ago, and reports of cervical cancer deaths today would reflect sexual activity at an even earlier time.
All reports from China today that indicate the low incidence of premarital intercourse, venereal disease, and early marriage make the point that these observations ane in contradistinction to the situation prevailing a few decadies ago. Thus the concurrent observations ane not contradictory, but rather they hold out the possibility that the incidence of cervical cancer in China may be seen to fall markedly in sucoeeding decades. -I am, etc.

London W.C.1

Steven H. LAMM

Beral, V., Lancet, 1974, 1, 1037.

\section{Jaundice in Acute Pustular Psoriasis}

SIR, - With regard to the case presented by Dr. D. J. Warren and others (25 May, p. 406), I should like to report a case of pustular psoriasis sharing one featurenamely, jaundice-with theirs.

A woman of 62 who had a three-year history of psoriasis with arthropathy treated with various drugs, including systemic methotrexate, was admitted with generalized pustular psoriasis. Pulses of intravenous methotrexate were given every 14 days and she remained stable for six weeks, when she developed a spike of temperature. She was started on fusidic acid and clindamycin (because of the report by McFadyen and Lyell ${ }^{1}$ that antistaphylococcal treatment induces remisthat antistaphylococcal treatment induces remissions of pustular psoriasis) and blood cultures were
taken, which later proved sterile. No other evidence of infection was found. She had had no methoof infection was found. She had

Three days later she developed jaundice accompanied by marked leucocytosis. The jaundice was unusual in that it was unaccompanied by malaise; that the serum bilirubin was virtually all conjugated (to a maximum of 11.0 out of $12.2 \mathrm{mg} / 100 \mathrm{ml}$ ); (to a maximum of 11.0 out of $12.2 \mathrm{mg} / 100 \mathrm{ml}$ ); antibiotics were stopped and had returned almost to normal before any abnormality in the transto normal before any abnormality in the transaminases and alkaline phosphatase was noted; and finally that the leucocytosis reached very high
levels $\left(55,000 / \mathrm{mm}^{3}\right)$, rising and falling in parallel levels $\left(55,000 / \mathrm{mm}^{3}\right)$, rising and falling in parallel
with the bilirubin level. Thrombocytopenia with the bilirubin level. Thrombocytopenia weeks later and at necropsy there was a small, pale liver, histological examination showing moderately acute hepatitis with mixed cell infiltration of the portal tracts and severe fatty degeneration sparing the periportal areas.

The type of jaundice was difficult to classify, the conjugated bilirubin making it closest to, but much more severe than, the Dubin-Johnson type of congenital hyperbilirubinaemia. The subsequent rise in transaminases and alkaline phosphatase and the postmortem histology also make this diagnosis unlikely. It seems unlikely that the jaundice was due solely to oligarmia, pustular psoriasis, or methotrexate treatment. It seems possible, in view of the temporal relationship, that the giving of antibiotics and the jaundice were related. Both antibiotios conoerned are excreted by the liver, and fusidic acid can compete with bromsulphalein for its excretory parhway, suggesting that an acquired intracellular transport defect could have developed.

However, it also seems possible that the liver in pustular psoriasis is predisposed to damage by the factors mentioned above, and it might be prudent to avoid drugs excreted by the liver in patients with generalized pustular psoriasis.-I am, etc.,

Department of Dermatology,

James A. Craig Royal Infirmary,

1 McFadyen, T., and Lyell, A., British foumal of 